\title{
A Contribution to the Study of the Structure of the Salivary Gland Chromosome in Chironomus ${ }^{1}$
}

\author{
By \\ Jun-ichi Morita \\ Osaka-Kotogakko, Osaka, Japan \\ Received Hay' ${ }_{3}, I_{1}+1$ \\ Contents \\ Page

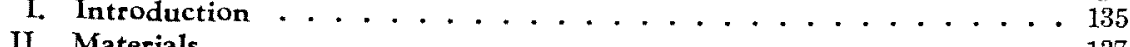

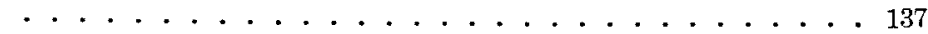 \\ III. Methods . . . . . . . . . . . . . . . . . . . . . . . . . . . 1313 \\ a). The aceto-carmine preparation . . . . . . . . . . . . 139 \\ b). The acid-vapour treatment . . . . . . . . . . . . . . . 139 \\ IV. Observations and considerations . . . . . . . . . . . . . . . 140 \\ a). Observations with aceto-carmine preparations . . . . . . 140 \\ A). Chironomus dorsalis Meigen. . . . . . . . 140 \\ 1. Chromonema . . . . . . . . . . . . . . 142 \\ 2. Shape of the synapsed chromosome . . . . . . . 144 \\ 3. Constriction of chromosome ........... 144 \\ 4. Twisting of the homologous partners ...... . 145 \\ 5. Cross striation and the question of spiral structure . 151 \\ 6. Chromomeres and cross striation ........ 152 \\ B). Chironomus sp. ............... 155 \\ b). Observations on the acid-vapour treatment. . . . . . 155 \\ 1. Chromomeres and chromonemata in fresh state . . 155 \\ 2. Summary of the results of the acid-vapour treatment 157 \\ v. Summary . . . . . . . . . . . . . . . 158 \\ VI. Addenda . . . . . . . . . . . . . . . . . . . . . . . . . . . . . . . . . . . . . 159

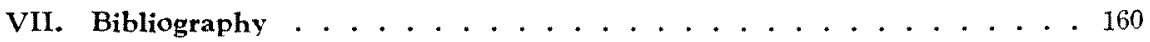

\section{Introduction}

The spireme nucleus, which is found in the salivary gland and other organs of the Dipteran larva (cf. Makino 1938), was first discovered, as is well known, by Balbiani (1881) in Chironomus. In 1933, Heitz und Bauer demonstrated in the Malpighian tubule of Bibio hortulanus that the spireme is nothing but a set of chromosomes, each two homologues of which are synapsed and consequently appearing haploid in number. They demonstrated also the regularity of the cross striation of chromatic substance arranged for the most part perpendicularly to the long axis of the synapsed chromosome. These facts were confirmed almost at the same time or soon thereafter by Painter (1933) in Drosophila, by King and Beams (1934) in Chironomus, by Geitler (1934) in Simulium and by many others in several other species.

The structure of the spireme-like chromosome, especially the real

1 Aided by a grant from the Japan Society for the Advancement of Cytology, to which the writer's most appreciative thanks are ciue. 
state of the cross striations in the chromosome, has for a long time been and is still a vexed question. Once, it was disputed whether the cross striations make together a spiral (or spirals) along the periphery of the long axis of chromosome (v. Herweden 1910) or whether they are discs or rings placed almost percendicularly to the long axis of chromosome (Balbiani 1881, Leydig 1893, Erhard 1910, Bolsius 1911).

Alverdes studied, in 1913, the development of the spireme-like chromosome in Chironomus and showed that the spirals in the chromosome of the younger larva become discs in the chromosome of the larva about $0.5 \mathrm{~cm}$ long, through disintegration and subsequent junction in a curious fashion i.e. the spiral is disintegrated in many pieces and these pieces subsequently join themselves so as to form numerous separate discs.

Since the work of Heitz und Bauer (1933) the real nature of the cross striation was again questioned. And now, although there are some authors who still believe in the spiral nature of the cross striations (Kaufmann 1931, von Willer und Audova 1933, Sinotô and Yuasa 1985 and others. Kuwada 1937 seems to accept the statement of Alverdes), the great majority of authors (Koltzoff 1934, Bridges 1935, Heitz 1935, Koller 1935, Muller 1935, Bauer 1936, Frolowa 1936, Buck 1937, Painter and Griffen 1937, Geitler 1934, 1938, and other authors) are of the opinion that the synapsed chromosome of the well developed larva is a pair of bundles of chromonemata produced from an original single pair of chromonemata ${ }^{1}$ by the longitudinal division occurring several times during the development of the larva, and that the cross striations are nothing but the rows of homologous chromomeres on these chromonemata, chromomeres of the same rank making together a disc (chromomere-aggregation of Heitz).

The opinion of Metz and his coworkers is different from those above mentioned. Their opinion is that the chromosome, at least in the fixed condition, is made up of a series of chromatic discs which, although connected by true chromosome material, are separated by layers of achromatic droplets. "Each two successive discs", they believe, "are separated by one layer of droplets embedded in the true chromosome substance, which extends longitudinally between and around the droplets from the one disck to the next (Metz 1939)". According to this view the delicate longitudinal lines are not threads (chromonemata), as considered by many authors, but optical sections of the material lying between the droplets, and consequently need not be continuous across the chromatic discs. Moreover, they believe that "fundamentally each chromatic segment is a thin, smooth disc, and that the granules, zigzag structures, etc., are modifications due to the treatment employed" (Metz 1935), contrary to

1 It is accepted generally that each original partner is already divided into two chromonemata. 
the universal conception that the granules (chromomeres) existed primarily and the dises are produced secondarily by the closer arrangement or by the fusing together of those granules. In short, Metz and his coworkers, if I follow the expression of Buck (1937), raised serious objections to the view that there is any identity of the longitudinal threads, which connect chromomeric granules along the length of the chromosomes, with the individual genonemes.

Their objection is based roughly on the following: 1) The number of chromonemata and granules to be expected from the increase of the sectional area of chromosome is too small. 2) The length of chromonema is too long to be expected. 3) Chromomeres are too large, and if we admit that the granules represent the higher but definite multiple, yet there is, in the case of some discs, a small number of small granules. 4) There is no uniformity in the number of chromomere in a definite disc of the chromosome of the same kind. 5) Materials of a dises may appear in the form of a single row of granules in one cell and two rows of granules in another even in the same gland.

As to the mode of twisting of partners, there are many gaps in our knowledge-we do not know whether the twisting occurs in constant number and position and in a constant direction (s. Geitler 1938 page 113). Moreover, no satisfactory explanation has yet been given about the relation between twisting and constriction, which latter is seen abundantly in the chromosomes highly synapsed and which is claimed by Fieitz to appear in constant position in many cases. Geitler denies any relation between the twisting of partners and the constrictions of the chromosome.

As to the form of the synapsed chromoscme, Yasui (1935) describes it in Drosophila melenogaster as flattened i.e. tape-shaped, although many authors are agree on its being cylinder in form.

First, to get an accurate conception about the delicate longitudinal lines and cross striations in the chromosome and second, to examine the mode of twisting and constrictions and moreover to examine whether there exist any relation between the twisting and constrictions are the chief purposes of the present investigation. To what degree the constancy of size and position of chromomeres and cross striations can be maintained in the fixed preparation is another question to which an answer is desired.

\section{Materials}

The larvae of two species of Chironoms, obtained during the months from May to December from ditches in the vicinity of Osaka, were examined, taken fresh from nature or, after being kept for some time in 
the laboratory. The ones which were used chiefly were the larvae of Chironomus dorsalis Meigen ${ }^{1}$ The other, a little larger and which I used only as reference, I was unable to determine the species of, and so I shall refer to it as Chironomus sp.

The characteristics of the larvae, the salivary glands and the chromosomes of both species may be summed up as follows.

Chironomus dorsalis Meigen

1) The larvae pupate at about 1.3 $\mathrm{cm}$ long.

2) There are two pairs of respiratory sacks ( $1 \mathrm{~mm}$ long in the front sac and $1.5 \mathrm{~mm}$ long in the hinder sac in the lavae of 1.0 $\mathrm{cm}$ in length) on the tenth segment and none on the ninth.

3) Salivary gland of about 1.0 $\mathrm{cm}$ long larva is large in size and consists of 52 cells, right and left glands together (average in nine individuals which contain $45-57$ cells).

4) Two nucleoli are situated each in the middle part of the chromosome I, and at the end of the chromosome IV.

5) Chromosomes are generally thick and short.

6) Synapsis of the partners is so intimate in the larvae more than $1.0 \mathrm{~cm}$ long that the twisting of partners is not easily recognized.

7) Cross striations in the chromosomes are distinct even in the fresh preparation in the larvae more than $1.0 \mathrm{~cm}$ in length.
Chironomus sp.

1) The larvae pupate at about 1.3 than that of Chironomus dorsalis Meigen before pupating.

2) Besides two pairs of longer respiratory sacks than in the case of Chironomus dorsalis Meigen on the tenth segment, there is one more pair of short appendages on the ninth."

3) Salivary gland of about 1.2 $\mathrm{cm}$ long larva is small in size and consists of 43 cells, right and left giands together (average in nine individuals which contain $34-48$ cells).

4) Two nucleoli are situated each at and near the middle part of two of the three large chromosomes and not at the end of the chromosome IV.

5) Chromosomes are generally thin and long.

6) Synapsis of the partners is not so intimate as in Chironomus dorsalis Meigen, and consequently the twisting of the partners is evident.

7) Cross striations in the chromosomes of the fresh preparation are not distinct even in the larvae $1.2-1.3 \mathrm{~cm}$ long.

1 I express here my hearty thanks to Dr. Y. Tokunaga, assistant professor at the Imperial University of Kyoto, who identified the species.

2 In larvae less than $0.8 \mathrm{~cm}$ long, it seems impossible to distinguish both species because the respiratory sacks on the ninth segment are perhaps not yet produced even in Chironomus sp. 
Almost all the cells in a gland have chromosomes of similar age except a few which are delayed in their development. The present study is based on the cells of normal development of the larvae of about $1.0 \mathrm{~cm}$ long, except when noted to the contrary.

\section{Methods}

The examination of the structure of chromosomes was executed in two ways: the one with the aceto-carmine preparations (total, more than 107 individuals, chiefly of Chironomus dorsalis Meigen and partly of Chironomus sp.) and the other with fresh preparations treated with acetic acid vapour under the microscope (totalling more than 80 individuals, wholly of Chironomus dorsalis Meigen).

\section{a). The aceto-carmine preparation}

The aceto-carmine solution was made after Frey-Schneider's procedure: a saturated solution of carmine in half-diluted glacial acetic acid. The salivary glands of the larva were immersed in the solution on the slide glass for 15-20 minutes before the cover glass was put on. A natural and sufficient pressure is given by the weight of the cover glass when we take out the excessive fluid from under the cover glass with a blotting paper. Highly pressed preparations are not always good unless the chromosomes are put out of the cell. Even in the latter case, the chromosomes serve for study only partly and not as a whole, because they are torn or stretched usually, and consequently we can not catch all the members in one nucleus at their natural ratio.

I generally used newly made preparations, but sometimes a week to two months old ones. It is interesting to note, in addition, that the acetocarmine preparations of one year old, if they have been well kept without evaporation through the sealing with a mixture of paraffin-vaseline, do not differ remarkably from those newly made, except that the chromomeres in the cross striations become somewhat indistinct through coalescing somewhat more with the neighbouring chromomeres of the same rank.

\section{b). The acid-vapour treatment}

The treatment with acetic acid vapour was executed as follows (Fig. 1). Under a cover glass $(\mathrm{Cg})$, which is put upon the moist chamber (Mc) containing ca. 3 c.c. of water, is suspended the salivary gland immersed in the body fluid of the larva and covered with paraftin oil to avoid evaporation ( $\mathrm{Hd}$ ) - "fresh preparation" in my description. A small quantity (ca. 1 c.c.) of appropriately diluted glacial acetic acid is introduced into the water of the moist chamber by a pipette $(P)$. The acid 
evaporates and penetrates in the hanging drop to enter next into the cell and nucleus_- "acid vapour treatment" in my description. We watch it for several minutes and sometimes furthert

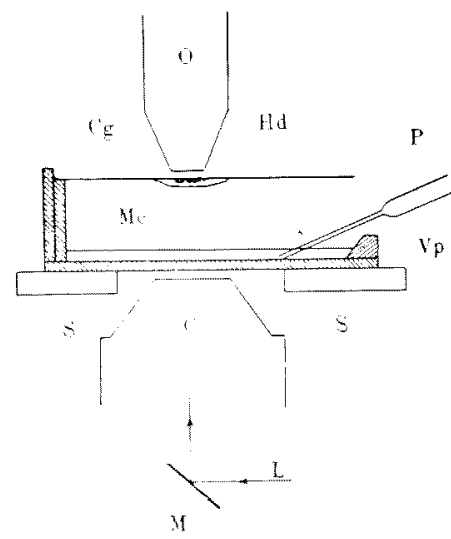

Fig. 1. Microscope equipped with moist chamber. C. Condensor, $\mathrm{Cg}$. Cover glass, Hd. Hanging drop, L. Light, M. Mirror, Mc. Moist chamber, O. Objective lens, P. Pipette, S. Stage, Vp. Vaseline-paraifin. ture as chromomeres and cross striations of the chromosome. This is why I adopted the method of acid vapour ireatment.

\section{Observations and considerations}

\section{a). Observations with aceto-carmine preparations}

A. Cbironomus dorsalis Meigen

Chromosomes are in four pairs and may be classified in terms of I, II, III and IV, arranged according to their length, chromosome I being the longest (Fig. 2). Each of them are synapsed completely, and the twisting of the homologues are usually difficult to detect in larvae more than $1.0 \mathrm{~cm}$ long, because they contact tightly, while the twisting is easily seen as partners contact loosely in young larvae beneath the length, as the following authors have pointed out: Frolowa (1937) in Drosophila, Buck (1937) in Sciara, and Painter and Griffen (1937) in Simulium. In this respect Buck says: "In the early embryonic gland homologous chromosomes are somatically paired, but not fused in synapsis." The fact that two partners lie tightly synapsed in the old chromosome may

1 After 15-20 minutes, structures of the chromosome become obscure owing to. the evaporation of the fluid of the hanging drop. 
be explained, beside through the attraction power between the homologous parts, on the assumption that their component chromonema have increased in number, enlarging at the same time the volume of chromosome and consequently increasing the lateral pressure beyond what is found in the young. As to the cross striations, the condition is reversed, i.e. they are

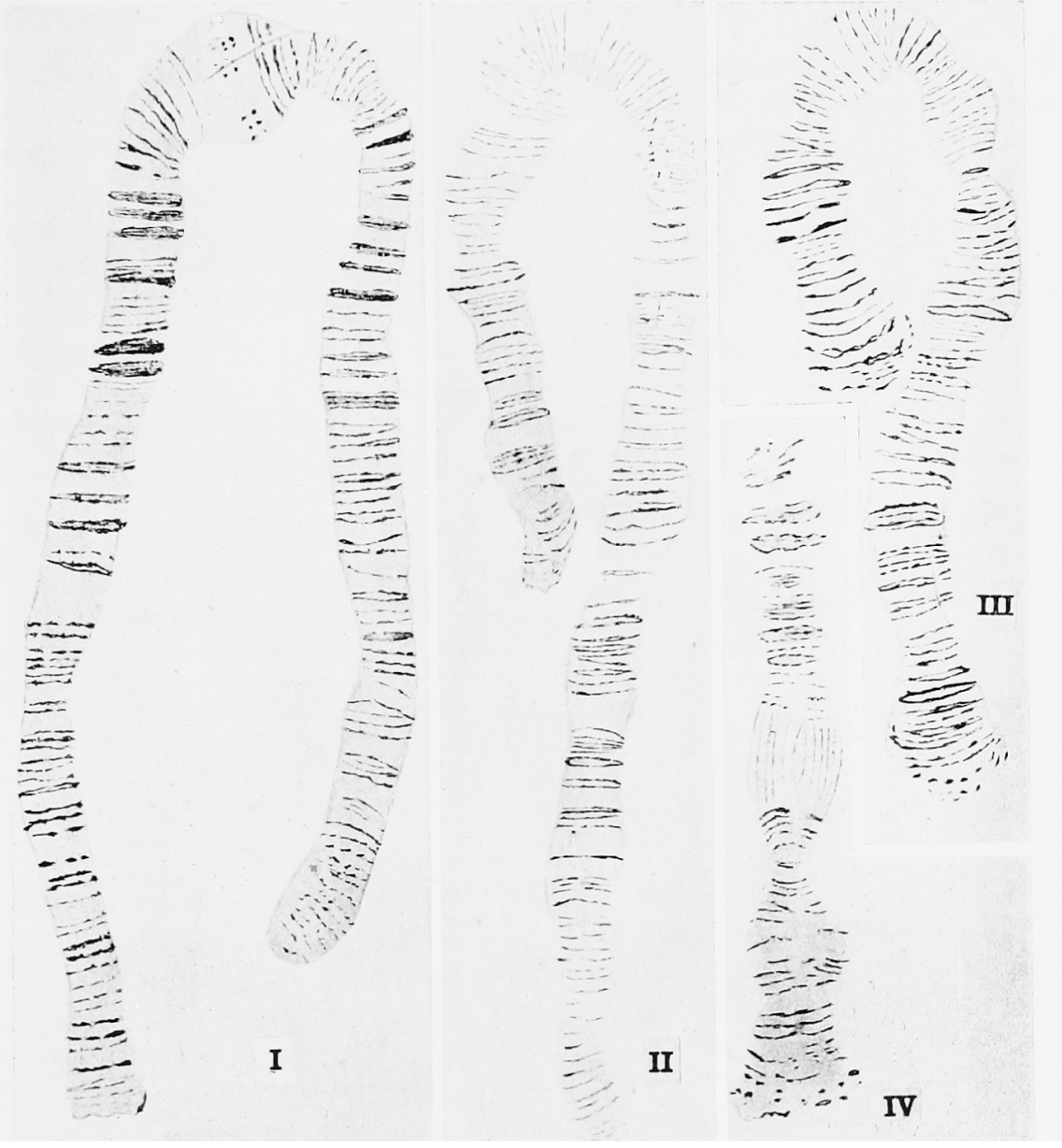

Fig. 2. A set of the salivary gland chromosomes (I-IV) of Chironomus dorsalis Meigen. Although not shown in the figure, there are two nucleoli: one at the middle and dilated part of the chromosome I, and the other at the expanded end (lower end in the figure) of the chromosome IV.

distinct both in fresh and fixed preparations in larvae more than $1.0 \mathrm{~cm}$ long, while they are not seen in the fresh or are not conspicuous even in the fixed preparations in larvae less than the length. Here, we must assume a change, at least, in the physico-chemical condition of the chromomeres. 
The length of the four chromosomes were measured in eight cells of a preparation of a larva of $1.0 \mathrm{~cm}$ long.

microns

Chromosome I 124-184 microns, average in eight cells being 156

Chromosome II 120-180 microns,

do

150

Chromosome III 90-140 microns.

do

112

Chromosome IV 32-68 microns,

do

49

The mode of arrangement of the cross striations on both sides of the nucleolus of chromosome I are quite easy to distinguish. Every point in chromosome IV is also quite easily distinguished cwing to the existence of chiasma, a portion where two partners cross constantly distinct (Fig. 6). Thus I used chromosomes I and IV chiefly (usually putting aside chromoscmes II and III, as they are not so distinct as I or IV) to scrutinize the condition of the delicate longitudinal lines (chromonemata), chromomeres, cross striations, the mode of twisting of a homologous pair, and the state of constrictions of the chromosome.

\section{Chromonema}

The synapsed chromosome of a $1.0 \mathrm{~cm}$ long larva looks like a cylinder. But they are in reailty two cylinders twisting. Each cylinder consists of bundle of longitudinal threads (chromonemata). According to Metz and his co-workers these longitudinal lines are not chromonemata and are not really thread-like in nature. "Fundamentally they represent," say Metz and Laurence (1937), "the interfaces, with more or less chromatic material, between the droplets separating one disc from the next" Buck (1939), after immersing the salivary gland in a hanging drop of isotonic Ringer's over the vapour of osmium tetroxide for 15 to 18 hours at 15 degree centigrade, saw "the stage-by-stage reversible transformation of staggered transverse rows of achromatic droplets (honey comb) into longitudinal parallel threadlike striations", supporting Metz's view that "the latter are artifacts" Nevertheless, so far as I have examined, they are continuous longitudinal threads, although these longitudinal threads are not easily detected everywhere in the chromosome. Bauer has already seen them clearly in Chironomus. Geitler also say that they are seen in the nucleolar part and at the expanded end of chromosome. I found them usually evident in the nucleolar part of chromosome I, near the chiasmic part of chromosome IV, at the expanded end and at the stretched portion of any chromosome.

Whether this thread in the salivary gland chromosome corresponds to a single chromonema of the sort clearly seen in some ordinary chromosomes or whether they correspond to a multiple of it as several american authors (Metz, Buck, Painter etc) admit, is difficult to decide at present.

But, the numbers of chromonemata and granules to be expected from 
the increase of the sectional area of chromosome are too small if we follow the calculation of Metz and Laurence (1937) and Buck (1937). And moreover according to Hertwig (1935) the valency of the salivary gland nucleus of Drosophila melanogaster is 256 or 512. Thus I follow for the present, together with other authors, the opinion that "it may very well be that the visual number of threads is much lower than the actual number (Bridegs 1937)", and consequently a single microscopic thread represents a bundle of chromonemata of the other ordinary cell.

Metz and Laurence (1937) drew a figure (Fig. 8 loc. cit.) with an appearance of network, and they explain it as "moderately stretched regions of the type in which the chromatic material is mostly localized in blocklike granules connected by delicate lines" I saw such chromosomes very often. But it must be stressed that there are always two buncles of chromonemata in different levels-upper and lower under the microscope, running obliquely to each other (Fig. 3). The paragraph of Metz and Latrence (1937) that "in the undistorted chromosome, these short lines, for the most part, are not themselves aligned to give the appearance of continuous threads, but are staggerd. Those between two discs altelnate in position with those between the next two discs" is also to be explained in the same manner as above.

The distribution of chromonema in the chromosome as revealed by the existence of chromomere in the optical transverse (Fig. 4) and longitudinal

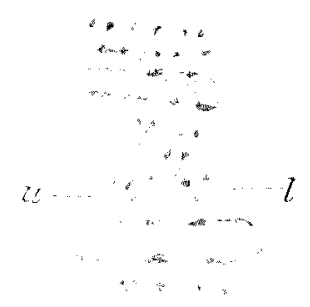

Fig. 3. A part of the middle portion of chromosome II of Chironomus dorsalis Meigen. 'Iwo bundles of chromonemata run obliquely to each other in upper (lt) and lower (l) positions under the microscope. (Fig. 13) sections is even as Bauer, Geitler, Emmens (1936) and others have described it, although Heitz, Muller, Painter and Frolowa believe that they are distributed only in the periphery.

Sometimes two bundles of chromonema are visible in one partner, as has been pointed out by Geitler (1934), Painter and Griffen (1937) both in Simulium, Buck (1937) in Sciara, and Frolowa (1937) in Drosophila. Two bundles of chromonema in one partner are revealed when they run obliquely, the two homologous partners being separated.

Metz, seeing that there are sometimes two discs and sometimes one disc at the identical place of the identical chromosome, writes that "The difference between the conditions in the two chromosomes is apparently due to a different distribution of chromatic and achromatic materials in the two (Metz 1937)" This case ought to be explained by the stretching of one disc and by the union of two discs (Fig. 14 and text of page 153). Moreover, Metz and Laurence (1937) saw that "In some cases the discs are sharp and clearcut, with relatively little chromatic material around 
the intervening droplets (Fig. 15); in others much of the chromatic material is in the latter position (Fig. 5, 6, 14, 17, 18)", and regards "both conditions are normal and may even be reversible" But if we know the process of fixation as described later we can not say that they are normal. In the explanation of fig. 5 loc. cit., Metz and Laurence (1937) says that it "also illustrates difference in number of droplets at different loci", but here two partners are twisting sometimes side by side (wide place) and sometimes in upper and lower position (narrow place), having many intermediate portions between these two extreme cases.

\section{Shape of the synapsed chromosome}

Although the synapsed chromosomes are circular cylinders in their usual form, they often become elliptical cylinders and sometimes tapeshaped, perhaps owing to the degree of preasure they receive laterally, the tape-shape being regarded a bit more pressed than the elliptical cylinder. These deformations of the circular cylinder may depend partly

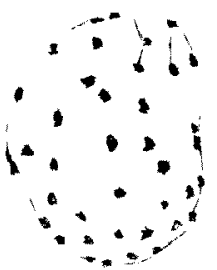

Fig. 4. An optical transverse section of a salivary gland chromosome of Chironomus dorsalis Meigen in the preparation of the acid-vapour experiment (three and half minutes after the acid treatment). Over twenty chromomeres are seen distributed evenly in the interior of the chromosome. on the paucity of the mechanically-resistent-substance in the interior of the cylinder, but chiefly on the lateral pressure it receives as the sequence of the contortion of the chromosome. The antinucleolar side of the chisma of the chromosome IV is the portion where two homologues separate constantly from each other. In this separated portion, both partners are very often tapeshaped in the aceto-carmine preparations (whether it is also tape-shaped in the fresh preparation, I could not ascertain). This portion is tape-shaped perhaps because here both partners contort themselves very much i.e. they rotate about 180 degree, often forming two loops.

The circular form of the optical transverse section of the chromosome is distinctly seen in the fresh preparation of the system of hanging drop (Fig. 4), because here the chromosomes are not pressed at all (cf. the chapter of acid vapour treatment).

\section{Constriction of chromosome}

There are many constrictions of various degree in all of the four chromosomes. The mechanism determining the occurrence of these constrictions may be primarily by the tortion of chromosome which originated in the molecular torsion.

Two partners in a synapsed chromosome can be compared to two twisted stems of taro plant which have imbibed water after being once 
dried. If they are contorted at one point they receive there lateral pressure and produce constriction. The greater the pressure the more conspicuous is the constriction. The pressure can secondly be strengthened by the following two factors: first that the partners, along with their ages, increase their volume, as Koller (1935) and Buck (1937) have shown, and give more lateral pressure than before', and second the resistance of the chromonema against the contracting force of the fivatixe acid acts as the stretching force to the chromosome and give more lateral pressure than before unless there is rotation to release the twisting."

The case in which the constriction occurs where there is no synapsis as in the case of chromosomes II and III of Drosophila melanogaster as observed by other authors can be explained also by the existence of tortion in each partner. Constrictions occur very often in constant position, but this is not always the case (cf. Fig. 8 a.b.c.).

Besides constrictions, there is often a constriction-like portion along the long axis of the synapsed chromosome. This is the place where two partners only cross without making a twist.

4. Twisting of the homologous partner's

A few definitions may be given here on the mode of synapsis. If two partners run parallel (side by side or in upper and lower positions in the microscope) they are said to be parallel (Fig. 5 a). If they cross without changing their horizontal levels, or if they change only their horizontal level i.e. the one ascend and the other descend without changing their horizontal position they are said to be crossing (Fig. $5 \mathrm{~b})$. If they cross two times, changing their horizontal or vertical level and becoming like a lope they are said to be twisting - a part of relational spiral of Darlington and Kuwada (Fig. $5 \mathrm{c}$ ). The
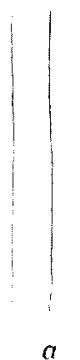

Fig. 5. Three modes of synapis of two homologues. $a$. parallel; $b$. crossing ; $\iota$. twisting. distance of the two points of crossing may be variable, sometimes great (obtuse twisting) and sometimes small (acute twisting).

I examined minutely and sketched, utilizing faithfully the fine adjustment, the mode of twisting of the chromosome IV in many cells of many preparations. I did it without any prejudice and found at least four different types of twisting (Fig. 7, II R, IV R, V R, VIII R).

1 This coincides well with the fact that the partners are synapsed tightly in the old chromosome.

2 This does not occur during the piocess of fixation as examined by the fixation with the acid-vapour under the microscope. 
Chromosome IV usually has four constrictions (Fig. 6), though sometimes three. If we regard the four constrictions as the usual type, and if we admit that the two partners can synays in all possible ways we have the following sixteen

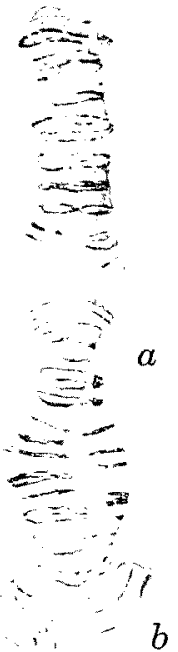

Fig. 6. Chromosome IV of Chironomus dorsalis Meigen which has four constrictions; upper two obtuse and lower two acute. a. The portion where two partners cross constantly distinct, and designated chiasma. $b$. The portion where nucleolus exists. possible types of twisting in the chromosome IV (Fig. 7) :

1) Homologous partners undulate standing side by side or in upper and lower position without making any twist, left (I L) and right (I R) hand undulations being possible.

2) Homologues twist one time at the nucleolar end, left (II L) and right (II R) hand twists being possible.

3) Homologues twist one time at the middle point, left (IIl L) and right (III R) hand twists being possible.

4) Homologues twist one time at the antinucleolar end, left (IV L) and right (IV R) hand twists being possible.

5) Homologues twist two times at the nucleolar and antinucleolar ends, left ( $\mathrm{V} \mathrm{L}$ ) and right $(V R)$ hand twists being possible.

6) Homologues twist two times at the nucleolar end and at the middle point, left (VI L) and right (VI R) hand twists being possible.

7) Homologues twist two times at the middle point and at the antinucleolar end, left (VII L) and right (VII R) hand twists being possible.

8). Homologues twist three times i.e. twist completely, left (VIII L) and right (VIII R) hand twists being possible.

I have seen, doubtlessly, one case of II $R$, two cases of IV $R$, two cases of $V R$ and one case of VIII $R$. It seems that $I$ have also seen $I L, I R$, and VII R. But I omitted them as there was some doubt. In all cases that I have clearly seen, the mode of synapsis is right handed, but it is only a matter of chance, because when I examined the direction of the upper partner in the chiasmic portion in many nuclei of one preparation, there were twelve right hand against nine left hand twistings.

Both sides of the nucleolus of the chromosome I have conspicuous characteristics, and are distinguished quite easily. I chose one side and sketched the identical parts in three cells of different preparations (Fig. 8). Here the twisting is not identical in three cells. They twist to right or to left, and the degree of twisting is different in three cells i.e. some- 


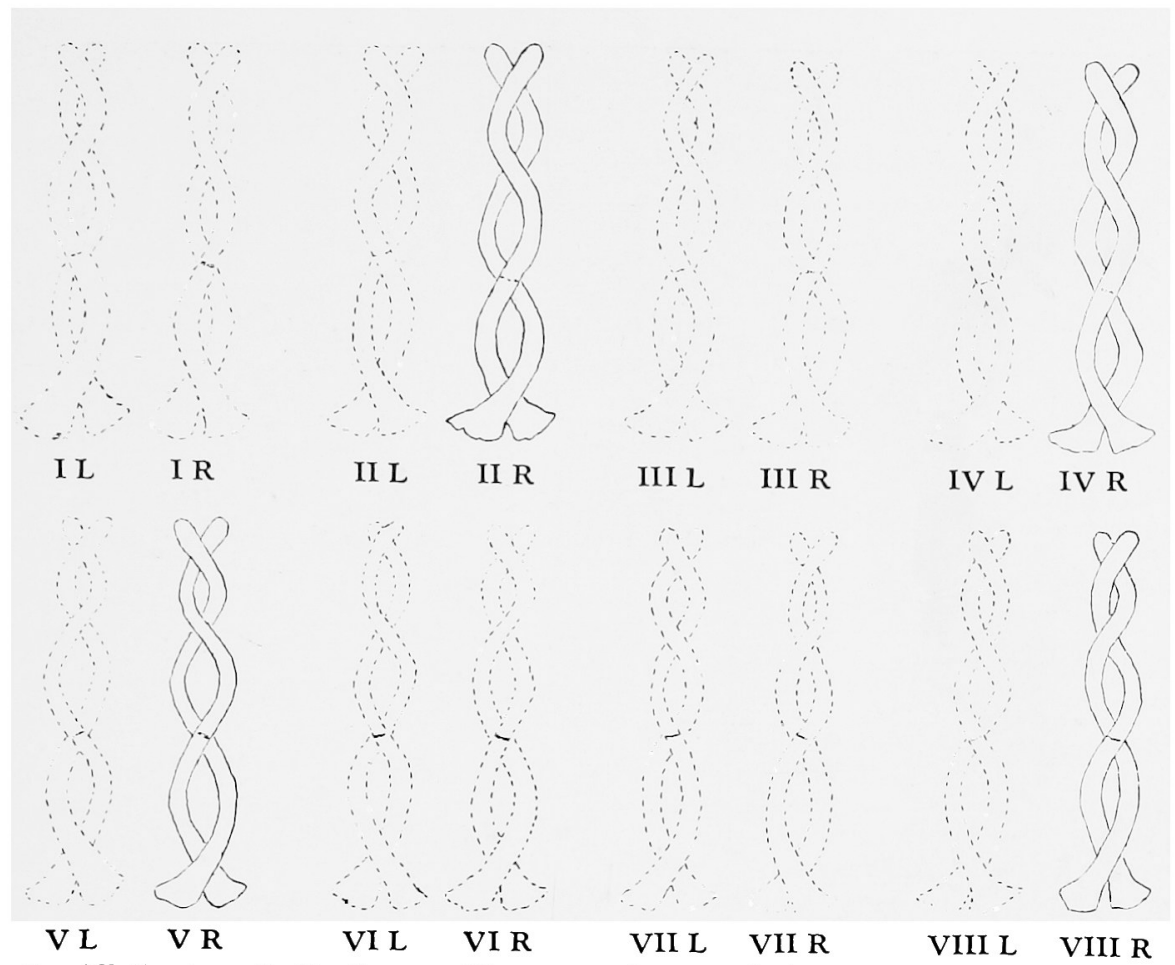

Fig. 7. All the hypothetically possible cases of synapsis in chromosome IV, which has usually four constrictions. Left- and right-handed are called according to the direction of partner at the point of chiasma (cf. Fig. 6). Starting from the nucleolar part (lower part in the figure), if the partner situated in the upper position runs to the left at the chiasmic portion, then it is termed left-handed, and if to the right, right-handed. Figures drawn with real lines are the cases doubtlessly seen, and the dotted lines are the hypothetically possible cases and not actually seen. The mode of twisting, which is usually quite difficult to see in the preparation (cf. Fig. 6) is exagerated in the diagram to make it easier to understand.

times acute and sometimes obtuse. A change in the direction of the twisting was often observed, although Koller (1935) says that "the coils turn in a constant direction."

I saw one case where two partners are separated completely for a long distance (Fig. 9). This can occur when the direction of the twisting is changed. This must not be explained by the heterozy'goty of the partner, because in other cells of the same preparation they are completely synapsed.

Geitler says that in Simulium the partners are united only in several chismashaped points and between these points they run completely separate. And he suggests that these pairing positions are perhaps constant. The chromosomes of Chironomus are different from those of Simulium. But the irregularity of the twisting of the partner in Chironomus suggests the existence of the irregularity of the similar kind in the union of partners also in Simulium. 

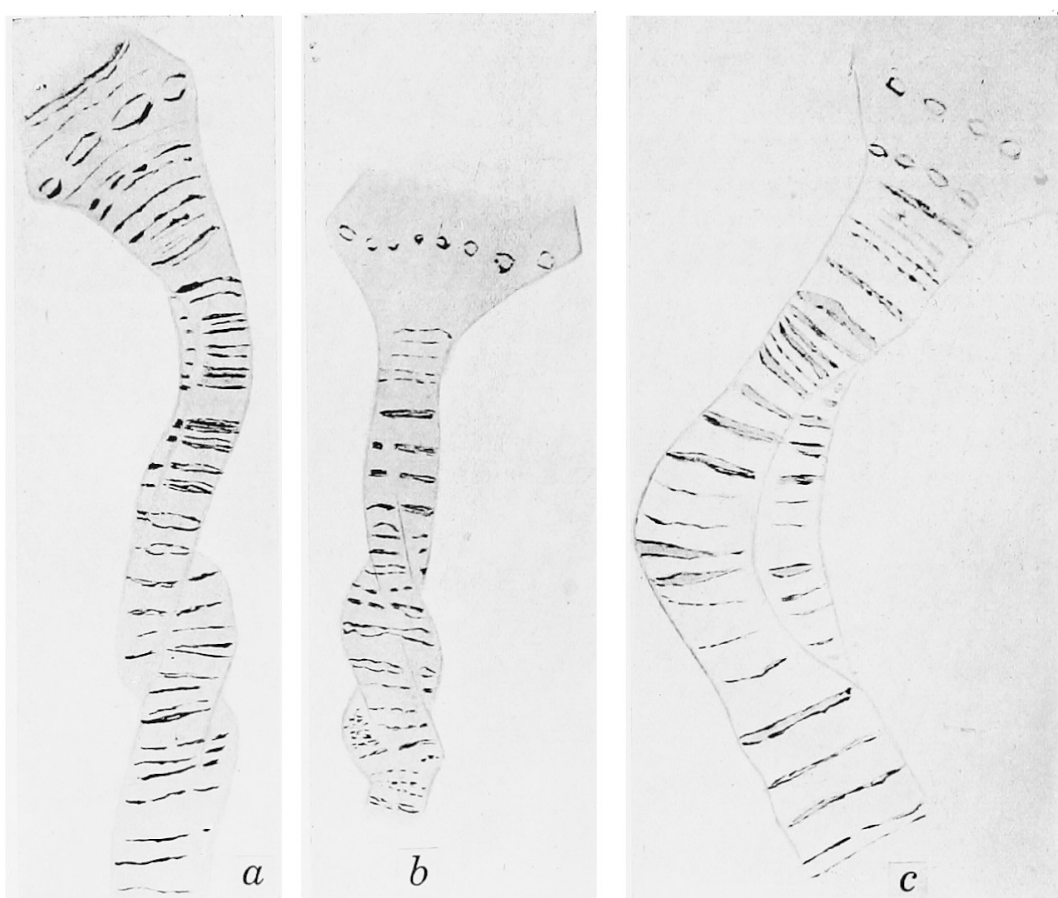

Fig. 8. Three identical parts at the nucleolar portion of the chromosome I. We'see different modes of twisting of the partners: $a$. left hand twist (so termed for convenience), $b$. right hand twist, $c$. no twisting.

Although Geitler denies any correlation between the constrictions and the twisting, so far as I have observed, where there are conspicuous.

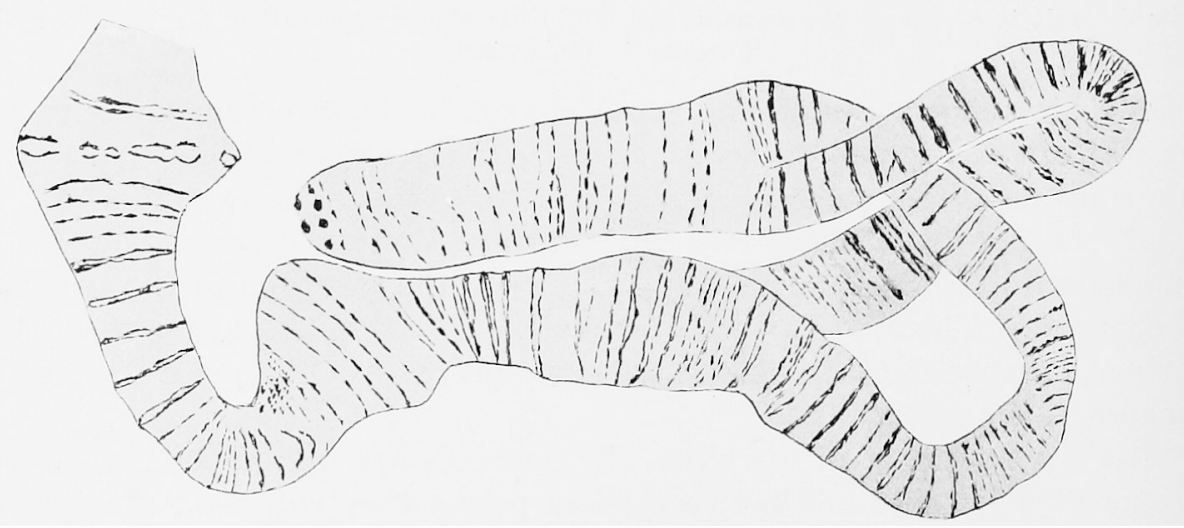

Fig. 9. The same arm of chromosome I as in Fig. 8. Two partners are separated by a long distance.

constrictions we see a twisting of the partners in almost all the cases, although the constriction-like portions (i.e. narrow portions) are produced only by the mere crossing without twisting. 
The existence of two homologous partners in apparently one chromosome is not always easy to detect as Koller (1935) and others have already pointed out. There are some portions in which it is quite impossible to detect the existing of the partners. Cases mentioned in the following are, however, to be taken as sign of their existence.

a) A cross striation of the chromosome appears continuous when we take the upper optical longitudinal section of the synapsed chromosome, while it appears discontinuous and not in the same line at the lower optical section. The osculating plane of the homologous partners in this case is perhaps intermediate between the vertical and horizontal direction. And if the optical section passes through the upper level (dotted line $a a^{\prime}$ in the Fig. 10), the cross striation appear as continuous lines while it becomes two lines in the lower optical section( dotted line $b b^{\prime}$ in the same figure) provided that there the homologous cross striations are

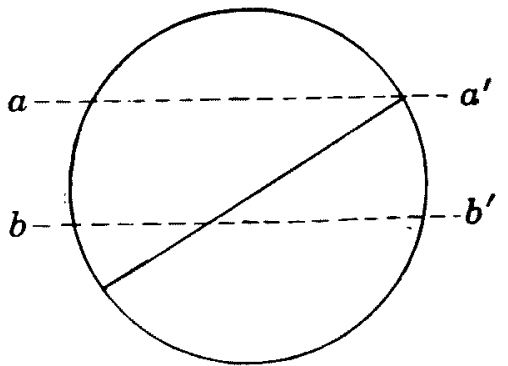

Fig. 10. A diagrammatical transverse section of a chromosome to explain the difference of images according to the difference of levels of the optical longitudinal sections $\left(a a^{\prime}\right.$ and $\left.b b^{\prime}\right)$. More detailed explanations in the text. slipping.

The slipping of the homologous cross striations is not impossible, although the homologous cross striations lie usually in a line. According

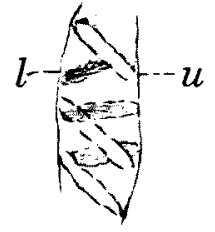

Fig. 11. Two homologous partners cross in upper and lower position and consequently the cross striations of the upper partner run obliquely to those of the lower partner. In this image it aprears as if the chromatic part were a spiral. Chromosome of Chironomus dorsalia Meigen, Aceto-carmine preparation. to Friedrich-Freksa, the conjugation is explained by the electrostatic attraction between the homologous parts of the chromosome. The attraction power between the non-homologous parts should be smaller. But the synapsis of two homologous chromosomes must be the sum of the synapses of many integrated parts. And the two partners are not synapsed strictly straight; rather they are twisting. Therefore the approaching of the homologous parts can be sometimes complete and sometimes incomplete. This explanation admits the incomplete synapsis of the homologous parts, i.e. the slipping of the homologous cross striations, to be a matter of possible. Horton (1939) recognizes that "the inversion of a band does not prevent it from synapsing in its reversed position directly with a homologous band in another chromosome, and it is clear that the somatic synapsis does not depend entirely on the orientation of the band on the chromosome (p. 241)." 
But the possibility of the incomplete synapsis in the fixed preparation being the artefact produced by the fixative is not precluded. At any rate, we see often that the homologous cross striations do not lie in the same line in the synapsed chromosome.

b). The cross striations are oblique to the long axis of chromosome in the upper optical longitudinal section and transverse in the lower. This is because the two homologues stand in upper and lower position under the microscope and because the upper partner runs oblique to the long axis of the chromosome (Fig. 11).

There are some authors (e.g. Makino 1940, a discussion with the present author on the sixteenth annual meeting of the Japanese association for the advancement of science at Keijo, Korea) who are apt to consider that two partners in a synapsed chromosome stand strictly side by side, and if the twist occurs, two partners twist together; in other words, they are regarded as touching each other always with a constant plane, even when they coil. To explain further, if two partners touch as in A of Fig. 12, i.e. on the plane $a a^{\prime}-b b^{\prime}-c c^{\prime}$, at a definite point, then they must

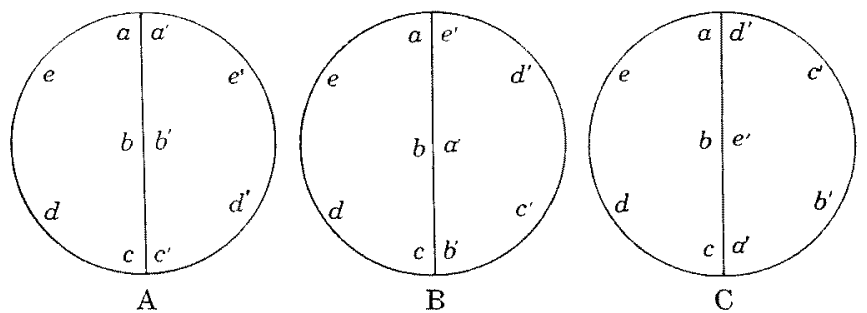

Fig 12. Diagrammatical transverse sections of three chromosomes to illustrate a part of the possible modes of synapsis. $a b c d e$ each represents chromonema, the number of chromonema in one partner being regarded as five for the sake of convenience. touch on the same plane everywhere along the long axis of the chromosome. But in reality they contact at every plane, sometimes standing side by side and sometimes crossing and sometimes twisting, i.e. two partners can change their osculating plane. That is, if they touch at a definite point on a plane $a a^{\prime}-b^{\prime}-c^{\prime}$, they can touch at the next point on the plane $a e^{\prime}-b^{\prime}-c^{\prime}$ or $\mathrm{ad}^{\prime}-\mathrm{be}^{\prime}-\mathrm{ca}^{\prime}$ ( $B$ and $\mathrm{C}$ of Fig. 12) or in any other possible way. Cooper (1938 p. 456) says that "it seems not improbable that at meiosis, regardless of the number (possibly four) of the chromonemata of the leptotene threads, the synapsing chromosomes are bilateral in organization, i.e. constructed in such a manner that each chromosome possesses but one, limited, pairing surface. The polytene chromosome (chromosome of multiple threads), on the other hand, may be considered radially symmetrical with respect to its synaptic surfaces." And only with the assumption of the radial symmetry, can we understand all.

Consulting the literature on this point we find everywhere the fact of twisting. Geitler writes: "Die Riesenchromosomen sind also in diesem Sinn nicht völlig gerad gestreckt (was übrigens auch für die Pachytän- 
chromosomen gilt) ; vielmehr sind die beiden Bündel je Partner schraubig umeinander gewunden (Reliktspiralen, Koller 1935) und die Partner selbst umschringen sich schraubig (Abb. 58,62)" (S. 112-113, 1938), and he does not describe "nebeneinander." The Fig. 1 of page 239, Fig. 3 of page 240, Fig. $7 \mathrm{~d}$ of page 246 of his paper of 1934 show the twistings without exception.

- Bauer (1936) writes, "die Partner sich flachen, weiten Spiralwindungen umeinandervickeln, ähnlich wie es Bridges (1935) auf sein schönen Abbildungen für Drosophila darsellt" (S. 298 Bauer), and Bridges (1935) figures on pape 62 and on plate 2 the twisting, though the latter is not shown in his later publication (1938).

Buck (1937) says, "shortly before the larva hatches from the egg the doubled homologues become more closely associated and begin to twisi or twine about each other, caduceous fashion."

Some figures of other authors do not show the twisting (e.g. Bridges 1988, Dobzhansky and Socolor 1939 etc) ; some figures, rather to the contrary, show the strictly side by side standing (e.g. Fig. 74 of Kuwada and some figures of other authors). The reason may be that they are figured so because the real state of twisting is quite difficult to show as the synapsis is well advanced, in addition to the circumstance that it may not be so necessary to the purpose of those authors, or because they cling to the idea of strictly side by side (i.e. the bilateral symmetrical and not the radial symmetrical) synapsis of two partners.

5. Cross striation and the question of the spiral structure

The opinion that the cross striation of the salivary gland chromosome is of a spiral nature is perhaps partly drawn from the case of Fig. 11 i.e. when two partners cross obliquely and their cross striations are therefore arranged obliquely. The spiral state of the $0.5 \mathrm{~cm}$ long larva of Alverdes may be explained partly by the condition above mentioned (and this I could almost ascertain in the larvae $0.3-0.5 \mathrm{~cm}$ long) and partly by the fact that the coils of Alverdes are twisted partners themselves, not corresponding to the cross striations in the chromosome. The stages of Alverdes where the spiral becomes discs must surely be images like that of Fig. 11.

Many observers recognize the partial existencec of a spiral: I myself saw it several times. But keeping in mind that what is apparently one chromosome is in reality two synaptic mates and that these two synaptic mates can stand under the microscope, side by side or in upper and lower position, twisting right and left, sometimes changing the direction of twisting, I could explain all the cases of apparent spiralling without adopting the spiral theory.

The idea that the cross striation may exist in a spiral manner or in a ring form may be completely abandoned if the duct of the salivary gland, 
which is a hollow cylinder and has also cross striations, is compared to the salivary chromosome. If the cross striation of chromosome is of spiral or ring structure, the optical longitudinal section must be like that of the duct (Fig. 13). The chromosome is never of spiral or ring structure.

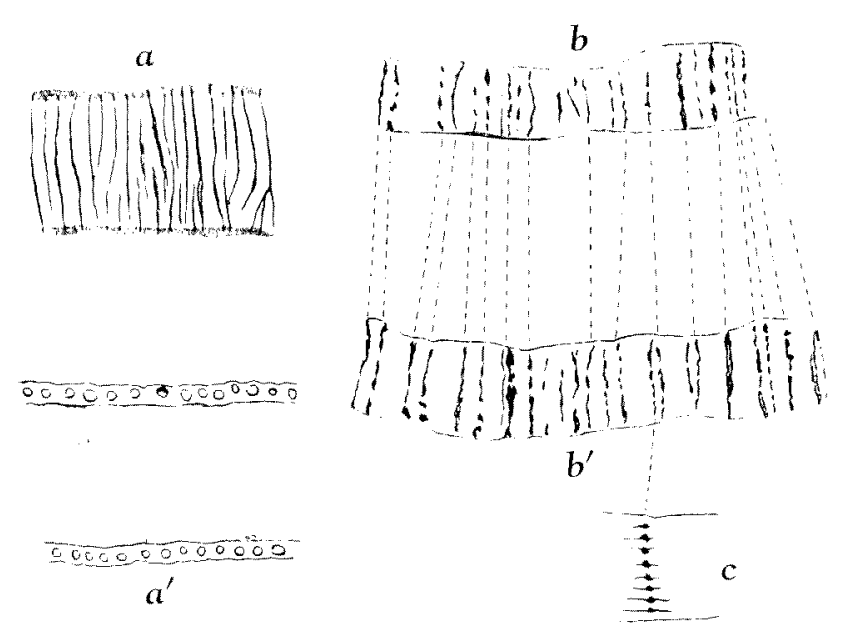

Fig. 13. Comparison between the duct $\left(a a^{\prime}\right)$ and a chromosome of the salivary gland $\left(b b^{\prime}\right)$. Same magnification. a and $b$-upper level. $a^{\prime}$ and $b^{\prime}$-optical sectoins of the middle parts. $c-a$ cross striation minutely drawn in higher magnification.

The fact that very often a cross striation in a definite position of a definite chromosome in one cell appears as several cross striations in the identical position of other cells of the same preparation may serve as an obstacle to the spiral theory. Lastly, the very fact that the chromonemata exist really almost perpendicularly to the cross striations, although Metz and his coworkers hesitate to recognize the existence of the chromonemata, is a most powerful obstacle to the spiral theory.

Von Willer, pulling the chromosome with the microneedle, accepts the existence of spiral structure. He thinks that if it were made up of disc, it should be disrupted. But even it were discs, there is no need to adopt the spiral theory as there are chromonema bundles to resist the pulling of the micromeedle.

\section{Chromomeres and cross striation} (cf. the chapter of the acid vapour treatment)

At the end of the chromosome, chromomeres are usually of the type of large granules of deep tint (heterochromomeres after Bauer). According to Bauer, at the end of chromosomes of the fixed preparation, there are vacuoles which have an achromatic center (achromatic granules). But as he could not find them at the identical site of the fresh chromosome, he thinks that the achromatic granules are produced through the swelling of ordinary granules by the action of acetic acid. I examined minutely the end of chromosomes of the aceto-carmine preparations and found always ordinary granules and not an achromatic granule. There, granules are not arranged in a straight line, but rather irregularly (zig-zag), con- 
trary to the case of euchromomeres in the other part of the chromosome. The cross striations which are made up of those granules are undulating and are interrupted at several spots. Two such cross striations standing approximately make an appearance of a row of several achromatic granules (vacuoles with inner achromatic space). Scrutinizing such apparent vacuoles with fine adjustment, I could not convince myself that they were vacuoles. In a fresh preparation, there are only several zig-zagrows of large granules of deep tint and not a vacuole, as Bauer has not already recognized. If acid vapour is given under the microscope, they remain likewise granules and do not become vacuoles.

There are usually one or two remarkable cross striation in the chromosomes I, II and III. It is a row of several elongated space with thick and deep contour. Bauer thinks such cross striation in Cryptochironomus defectus to be one cross striation whose chromomeres have swelled by the action of acetic acid, contrary to Bridges, who thinks it to be two cross striations approached.

So far as I have examined Chironomus, I could not get any other conclusion than that they are two cross striations approached, only differing from other cross striations in that they are interrupted at several points of a row. It is a matter of an usual occurrence that chromomeres of the advanced stage coalesce with each other in the same line and are interrupted in several spots forming several short curved lines in a row. Two such cross striations in an approached position make a remarkably thick cross striation, as above mentioned. The part of the nucleolus in chromosome I is broader and extends out into the material of the nucleolus. The cross striation here appears to be broken up into vesicles similar in size and appearance to those above mentioned on the chromomeres of the end of chromosome (Bauer 1936b, Paulsen and Metz 1938).

A thick cross striation of a definite portion of a definite chromosome is divided into several thin cross striations in the identical chromosome of the other cell (Fig. 14). I sketched minutely all the four chromosomes of three cells of a preparation. Comparing every type of chromosome with one other, I found it difficult, although it was possible, to identify. every cross striation. The general appearance is the same, but they are never the same in detail. This is perhaps because the approaching and the receding of the adjacent cross striations occur frequently. The receding of the cross striation is probably produced by the stretching force given at the time of preparation. The stretching of chromonema is always executed at the mid piece and not at the point of chromomere, as Geitler, Pfeifer, Darlington and Upcott (1939) pointed out. The approaching of the adjacent cross striations has already been noted by Bauer. Geitler and others, and I also shall soon describe it in the chapter of acid vapour treatment. 
The structure of the chromosome in the fixed preparation is true to natural condition in its gross appearance, but artefacts of some degree appear in finer details, as Doyle and Metz pointed out and as I myself shall show in the chapter of acid vapour treatment.

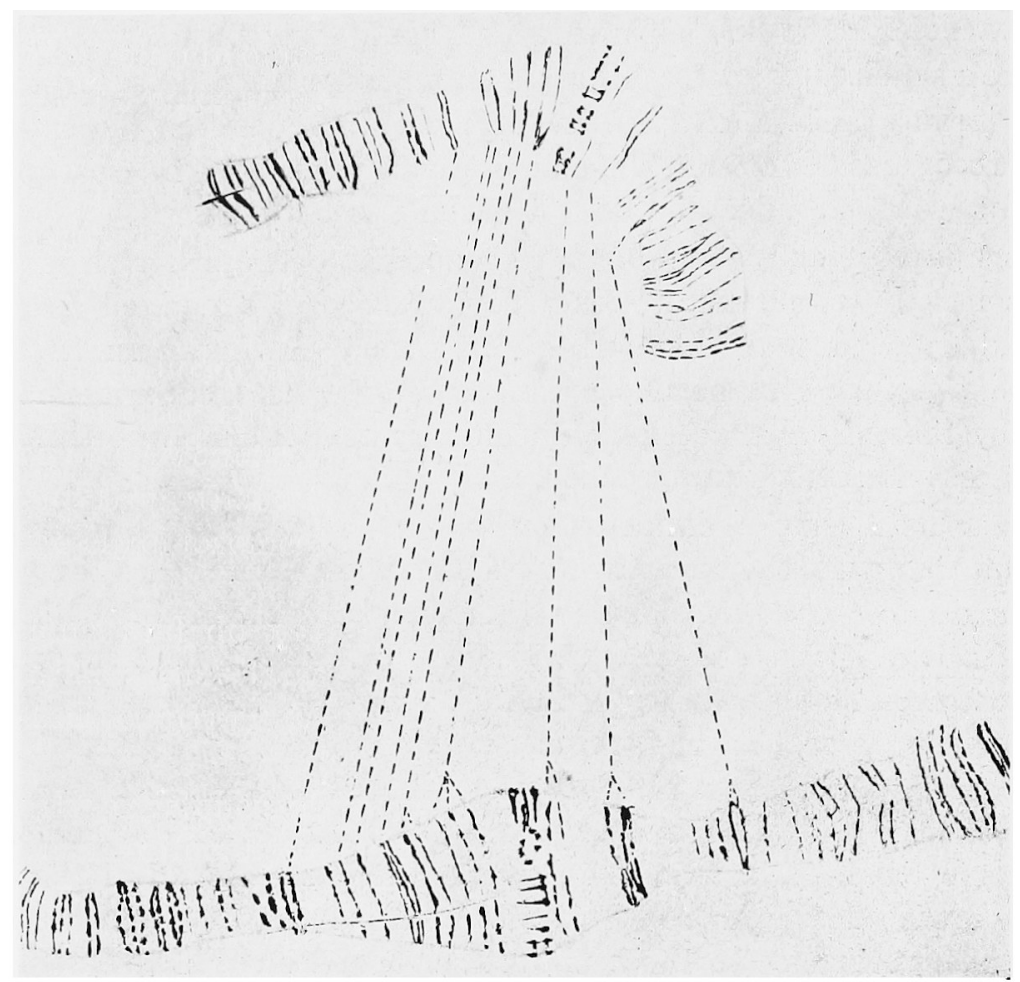

Fig. 14. The identical portions of the chromosome $I$ in two different aceto-carmine preparations of Chironomus dorsalis Meigen (larvae of the same length of $1.2-1.3 \mathrm{~cm}$ ).

Several miscellaneous observations have been brought together in the following.

a). Homologous cross striations in two partners are usually of the same type, but sometimes they show a difference. This may be due either to genetical reasons or to the difference in sensitivity to the action of the fixative i.e. difference of the degree of coalescing of chromomeres.

b). Chromomeres are usually of the same size in the same cross striation, but often there is a difference in size. This may be either artefact due to fixative or may be produced by the difference in the growth of chromomere.

c). Chromomeres of the same rank are usually situated in the same level of the long axis of the bundle of chromonemata. But sometimes they are not situated in the same level even in the same partner. This is 
evident when viewed from the side or from the front of the optical transeverse section of the chromosome. This may be because there is a difference in the degree of contraction in that portion of the chromonema along the long axis.

B. Chironomus sp.

Synapsis of two homologues is not intimate (there are some chromosomes in which the synapsis occur only in part of two homologues). Synapsis is intensified along with the age of the nucleus. But, even in the larvae more than $1.2 \mathrm{~cm}$ long, the existence of two synaptic mates is not so difficult to see. Cross striations are not distinct in fresh preparation, although they become evident after fixation as in the case of Sciara (as shown by many authors).

The chromosomes of the species are four in number, three large and one small. I did not classify the three large chromosomes, but the smallest, the fourth, may be called chromosome IV, as in the case of Chironomus dorsalis Meigen. The position of the nucleolus is different from that of the latter species. Two nucleoli are in two of the three large chromosomes, and none in chromosome IV.

Chromosomes of this species are usually thin and long and do not show any conspicuous constriction. This fact may be because that they did not increase in volume much after they had synapsed, contrary to the case of Chinomus dorsalis Meigen.

This species contributed much to the realization of the existence of two partners in the synapsed chromosome, even when it is difficult to detect them in Chironomus dorsalis Meigen, which is more advanced in the degree of synapsis than this species. About the conditions of chromomeres and cross striations, the results of the observation are the same as in the case of Chironomus dorsalis Meigen.

\section{b). Observations on the acid-vapour treatment}

The minute structure of the chromomeres and the cross striations were examined under vapour treatment. Materials were all Chironomus dorsalis Meigen. Before entering into the description of the acid-rapour treatment, several points may be mentioned in connection with the chromosome of fresh state.

1. Chromomeres and chromonemata in fresh state

Chromosomes are usually free in the nucleus, but they are attached very often at their end to the end of other chromosomes or to the nuclear membrane. Four chromosomes can be identified even in fresh state. 
Optical transverse cross sections are exactly made, because chromosomes are situated very often in an up-and-down direction, without being pressed in the slightest degree. The optical section thus obtained is usually circular and sometimes elliptical; never tape-shaped. Chromomeres are distributed evenly, never being restricted to the periphery. It is quite difficult to recognize that there are two partners in the optical cross section (Fig. 4).

Even in a fresh preparation, the cross striation is visible distinctly in larvae more than $1.0 \mathrm{~cm}$ in length. Cross striations are nothing but a row of chromomeres arranged across the long axis of the chromosome.

Cross striations and their component chromomeres may be classified in three types.

1) Cross striations which are invisible in fresh state and which become visible only after acid treatment are of the first type. Their constituent chromomeres are of very small dimensions and faint in tint (black under the microscope without any staining).

2) Cross striations and their constituent chromomeres are seen in fresh state (the second type). Chromomeres are of moderate size and of moderate tint. Some of the cross striations become quite distinct, their chromomeres increasing in tint after the acid treatment, while others remain as faint as in the fresh state, even after the acid treatment.

3) Cross striations are quite deep in tint, their constituent chromomeres being large in size (the third type). Chromomeres of the same rank make together a continuous and smooth line usually. This continuous line is often interrupted at several points. This type of cross striation may be regarded as the most aged, as Buck (1937) states that "the first bands which appear represent the heaviest bands of the definitive chromosome and remains relatively unaltered during development except to darken or to separate into doublets"

The acid-vapour treatment was executed with the chromomeres and cross striations of the second type. To execute the acid treatment, any one chromosome is caught by sight under the microscope, and a part of it is sketched minutely and then the acid vapour is given.

With acetic acid diluted to one sixteenth (water 15: glacial acetic acid 1) no change in the chromomeres is noticeable within the first three minutes.

With glacial acetic acid not diluted, chromomeres of the same rank which first become somewhat more distinct than in fresh state soon make a smooth and faint cross striation, the component chromomeres coalescing with each other to some degree. The cross striations next become heterogeneous i.e. dark and faint portions alternately appear and are sometimes disrupted, the disrupted part making often a vibration. In some cases, a few vacuoles come out from the chromosome and move 
about, finally adhering to some point of the same or neighbouring chromosome. At the same time, some granules make a Brownian movement in the nuclear lymph.

It is interesting to note that the two adjacent cross striations become one, making a compound cross striation, though it occurs quite rarely. Only the shortening of the distance between (i.e. the approaching of) the adjacent cross striations occurs usually. Ellenhorn, Prokofjewa and Muller (1935) and Caspersson (1936) saw by the ultravioletphotograph that a thick cross striation is composed of several cross striations. The fact is observable to some degree even in fresh state but is strengthened and becomes more easy to recognize by acid treatment. It is also interesting that sometimes there appear a few cross striations that were not seen until the time of acid treatment. This, of course, belongs to the cross striations of the first type.

With acetic acid diluted to one half (water $1:$ glacial acetic acid 1), there does not usually occur any union of two adjacent cross striations, but only the shortening of the distance between them. Some cross striations become heterogeneous to some degree. Disruption of any part of the chromosome never occurs.

With acetic acid diluted to one-fourth or to one-eighth, there does not usually occur the union of two adjacent cross striations nor the disruption in the cross striation. The shortening of the distance between several cross striations occurs. There appears a few cross striations that were not seen before the acid treatment, or cross striations theretofore indistinct become distinct.

It is noteworthy that chromomeres never make a Brownian movement in the euchromatin, nor in the heterochromatin part, although several large granules make a Brownian movement in the nuclear fluid and finally adhere to the end of chromosome. The Brownian movement of the chromomere should occur if the chromosomes were composed, as Metz and his coworkers insist, of chromatic material embedded in the achromatic material, without being linked by chromonema.

\section{Summary of the results of the acid- vapour treatment}

1) Chromosomes are rendered thin and short. The twisting of homologous partners, which was difficult to detect in fresh state. becomes more easy to see after the acid treatment. Chromosomes which have attached their end to the end of other chromosome or to the nuclear membrane are detached by acid treatment (Fig. 15).

2) Chromomeres coalesce to some degree with the neighbouring chromomeres of the same rank and produce a somewhat smooth and more faint cross striation than before. This cross striation then becomes some- 
what heterogeneous i.e. there appear deep and faint portions alternately, although irregularly.

3) Cross striations that were

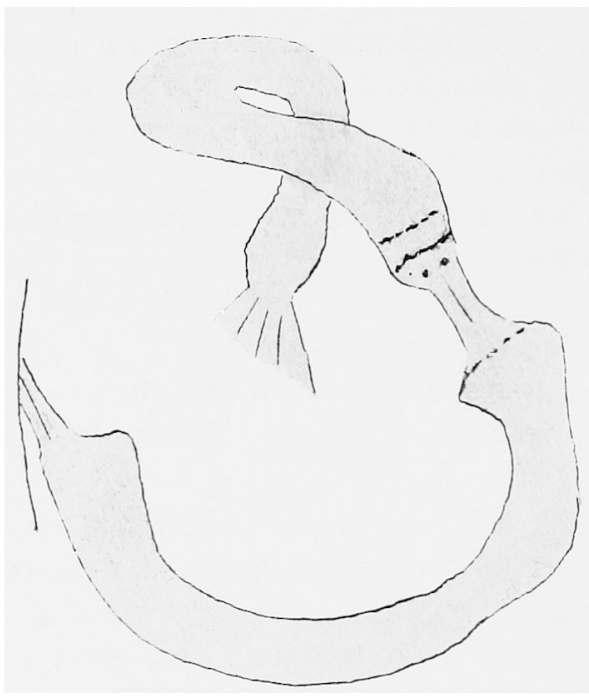

Fig. 15. Two chromosomes detachibg from the nuclear membrane and from one another soon after treatment with the vapour of acetic acid. not seen before the acid treatment become visible, and cross striations theretofore indistinct become distinct. Cross striations of these types are all composed of small or moderate-sized chromomeres.

4) Images produced by the acid treatment are like the images of carmine preparations and do not differ much from the state of the fresh preparation. The more concentrated the acid was, the greater the change of image, compared to that of the fresh state. The images produced by the treatment of acetic acid non-diluted is very different from those of fresh state e.g. coalescing of two adjacent cross striations or disruption in any part of one cross striation. But those treated with acetic acid with a concentration less than half dilution show no remarkable difference from fresh state, except, on the one hand, chromomeres of the same rank coalesce with each other to some degree and become somewhat faint and, on the other hand, cross striations that were not seen in fresh state make their appearance after being subjected to acid treatment.

\section{Summary}

1) Two types of Chironomus (chiefly Chiromomus dorsalis Meigen, and as reference Chironomus sp.) were examined by the usual acetocarmine method and also under acid-vapour treatment.

2) The longitudinal threads in the chromosome ought not to be regarded as chromatic interfaces between vacuoles as Metz and his coworkers insist upon. They ought to be regarded as continuous chromonema (single or multiple), with chromatic granules on it.

3) The synapsed chromosome consists of two cylinders twisting, as has already been recognized by many authors. The mode of twisting of two partners has been scrutinized in chromosomes I and IV. It has been demonstrated that a synapsed chromosome is like a rope where two partners twist around each other to right or to left, changing often the 
direction and the amplitude of twisting.

4) The shape of the transverse section of the synapsed chromosome is usually circular and often becomes elliptical but never tape-shaped.

5) Constrictions of chromosome are explained by the lateral pressure produced by the tortion of the chromosome and by two other factors.

6) Cross striations appear sometimes to be a spiral state, but they are explained always as discs.

7) Cross striations are produced by the coalescing of the chromomere of the same rank. The older the chromomere is the more advanced is the degree of the coalescing.

8) Images produced by the vapour treatment of the acetic acid correspond well. if the acid is not concentrated. to the imagines of acetocarmine preparations.

9) Images of carmine preparaiton correspond well to the natural images in their gross appearance, although many cross striations or a part of the cross striation is not natural in their finer details. This is clearly shown by the acid-vapour treatment under the microscope (as, for example, when chromomeres coalesce transversely or sometimes longitudinally). The artefacts of this sort may not prevent the argument of the gene loci as done by many authors of the genetic line.

10) With acid vapour treatment, cross striations become sometimes heterogeneous i.e. they become in one part distinct and in another part indistinct. Two cross striations unite sometimes ccmpletely to one cross striation.

\section{Addenda}

After the manuscript was completed, I saw the interesting work of M. Calvin, M. Kodai and R. Goldschmidt (1940). They treated the salivary gland with $\mathrm{NaOH}$ solution $\mathrm{P}_{\mathrm{II}} 9.2-10.4$, and then stained with aceto-carmine, smearing it then on the slide.

Although the time of appearance of the image is different according. to the degree of $\mathrm{P}_{\mathrm{HI}}$ (the greater the $\mathrm{P}_{\mathrm{II}}$ value the more rapidly appears the initial change) and although the image which appears (lamp-brush form) becomes invisible finally, the initial change is that the chromosome takes a lamp-brush form. Here "the chromosome typically shows two longitudinal beaded strings (chromatid), paired throughout their length, with each pair of homologous chromomeres connected by, a thin, sometimes beaded transverse thread"

According to their explanation of the structure of chromosome, the chromosome consists of primary and other (it may be called accessory) chromonemata and the bristles of lamp-brush is nothing but the loops, which are formed by the accessory chromonemata when the chromosomes contract longitudinally. 
I treated the salivary gland with ammoniacal vapour (non-diluted and diluted to one half, the method being the same as indicated in the paragraph of the method of acid-vapour treatment). There we see in the chromosome many longitudinal threads, as in the case of acid-vapour treatment, although somewhat more faint than in the case of the latter. And there are not two threads in the center of the long axis of the chromosome, as described by them. Some granules in the nuclear lymph make a Brownian movement, as in the case of acid-vapour treatment.

\section{vII. Bibliography}

1). Alverdes, F. 1913 Die Kerne in der Speicheldrusen der Chironomus-larve. Arch. f. Zellf. 9 : 168.

2). Balbiani, F. G. 1881 Sur la structure du noyau des cellules salivaires. Zool. Anz. 4: 662 .

3). Bauer, H. 1936 Der Aufbau der Chromosomen aus den Speicheldrüsen von Chironomus Thummi Kiefer. Z. f. Zellf. 23: 280.

4). - 1936 Beiträge zur Morphologie der Speicheldrüsenchromosomen. Zool. Jhb. Abt. allgem. Zool. u. Phys. 56: 239.

5). - 1938 Die polyploide Natur der Riesenchromosomen. Naturw. 26: 77.

6). Bolsius, H. 1911 Sur la structure spiralée ou discoide de l'élément chromatique dans les glandes salivaires des larves de Chironomus. La cellule 27: 77 .

7). Bridges, C. B. 1935 Salivary chromosome maps with a key to the banding of the chromosomes of Drosophila. J. Herd. 26 : 60.

8). - 1937 Correspondence batween linkage maps and salivary chromosome structure as illustrated in the tip of chromosome $2 \mathrm{R}$ of Drosophila melanogaster. Cytologia Fujii Jub. Vol. 745.

9). - 1938 A revised map of the salivary gland X-chromosome of Drosophila melanogaster. J. Herd. 29 : 11.

10). Buck, J. B. 1937 Growth and development of the salivary gland chromosomes in Sciara. Proc. Nat. Ac. Sci. $23: 423$.

11). - 1939 Micromanipulation of salivary gland chromosomes. Biol. Bull. $77: 330$.

12). Calvin, M., M. Kodani and R. Goldschmidt 1940 Effects of certain chemical treatment on the morphology of salivary gland chromosomes and their interpretation. Proc. Nat. Acad. Sci. vol. 26.

13). Caspersson, T. 1936 Über den ehemischen Aufbau der Strukturen des Zellkernes. Skand. Arch. Physiol. Bd. 73. Suppl. 8.

14). Cooper, K.W. 1938 Concerning the orgin of the polytene chromosomes of Diptera. Proc. Nat. Acad. Sci 24: 452.

15). Darlington, C.D. 1935 The internal mechanies of the chromosomes. I. The nuclear cycle in Fritillaria. Proc. Roy. Soc. London B. 118; 33.

16). Darlington, C. D. and M. B. Upcott 1939 The measurement of packing and contraction in chromosomes. Chromosoma 1: 23 .

17). Dobzhansky, Th. and D. Socolor 1939 Structure and variation of the chromosomes in Drosophila azteca. J. Hered. $30: 3$.

18). Doyle, W. L. and C.W. Metz 1935 Structure of chromosomes in the salivary gland cells in Sciara (Diptera). Biol. Bull. 69: 126.

19;. Ellenhorn, J., A. Prokof jewa and H.J. Muller 1935 The optical dissociation of Drosophila chromosomes by means of ultra-violet light. C.R.Ac. Sci. URSS $1(4): 234$.

2)). Emmens, C.W. 1936 Sections of Drosophila salivary glands. J. Hered. 27;351.

21). Erhard, H. 1910 Übar den Aufbau der Speicheldruisenkerne der Chironomuslarve. Arch. f. mikr. Anat. $76: 114$.

22! Frierich-Freksa, H. 1940 Bii der Chromosomenkonjugation wirksame Kräfte und ihre Bedeutung fur die identische Verdoppelung von Nukleoproteinen. Naturw. $28: 376$ 
23). Frolowa, S. L. 1936 Structure of the nuclei in the salivary gland cells of Drosophila. Nature 137: 319.

24). - 1938 Development of the giant salivary gland nuclei of Drosophila. Nature. 141 : 1014.

25). Geitler, L. v. 1934 Schleifenkerne von Simulium. Zool. Jahrb. Abt. allg. Zool. u. Phys. 54: 237.

26). - 1938 Chromosomenbau. Protoplasma Monographien Bd. 14 (Berlin).

27). Heitz, E. und H. Bruer 1933 Beweise für die Cromosomennatur der Kernschleifen in den Knäuelkernen von Bibio hortulanus L. Z. Zellf: 17. 67.

28). - 1935 Chromosomenstruktur und Gene. Z. induk. Abst. 70: 402.

29). Hertwig, G. 1935 Die Vierwertigkeit der Speicheldrüsenkerne und-chromosomen der Drosophila melanogaster. Z. induk. Abst. $70: 496$.

30). Herwerden, M.A.v. 1911 Über den Kernfaden und Nucleolus in den Speicheldrüsenkernen der Chironomus-Larve. Anat. Anz. 38 : 387.

31). Horton, I.H. 1939 A comparison of the salivary gland chromosomes of Drosophila milanogaster and D. simulans. Genetics 24: 234.

32). Kaufmann, B.P. 1931 Chromosome structure in Drosophila melanogaster. Amer. Nat. 65 : 555.

33). - 1938 Nucleolus-organizing regions in sulivary gland chromosomes of Drosophila melanogaster. Z. Zellf. $28: 1$.

34). King, R.L. and H. W. Beams 1934 Somatic synapsis in Chironomus, with special reference to the individuality of chromosomes. J. Morph. 56:577.

35). Koller, P.Ch. 1935 The movement of chromosomes within the cell and their dynamic interpretation. Genetica. $16: 447$.

36). - 1935 The internal mechanies of the chromosomes. IV. Pairing and coiling in salivary gland nuclei of Drosophila. Proc. Roy. Soc. London B. 118: 371 .

37). Koltzoff, N. 1934 The struccure of the chromosomes in the salivary gland of Drosophila. Science N.S. 80:312.

38). Kuwada, Y. 1937 Structure of chromosomes (japanese). Tokyo.

39). Leidig, Fr. 1883 Untersuchungen zur Anatomie und Histologie der Tiere. Bonn.

40). Makino, S. 1938 A morphological study of the nucleus in various kinds of somatic cells of Drosophila virilis. Cytologia 9: 272.

41). Metz, C.W. and E.H. Gay 1934 Organization of salivary gland chromosomes in Sciara in relation to genes. Pros. Nat. Acad. Sci, 20:617.

42). - , - 1934 Chromosome structure in the salivary glands of Sciara. Science N.S. $80: 195$.

43). Metz, C.W. 1935 Structure of the salivary gland chromosomes in Sciara. J. Hered. $26: 177$.

44). - 1936 Effects of mechanical distortion on the structure of salivary gland chromosomes. Biol. Bull. 71 : 238.

45). - 1937 A note on salivary chromosome knots in relation to problems of mutation and chromosome structure. Cytologia Fujii Jub. Vol. 614.

46). - 1939 The visible organization of the giant salivary gland chromosomes of Diptera. Amer. Nat. 73: 457.

47). Metz, C.W. and E. G. Laurence 1937 Studies on the organization of the giant gland chromosomes of Diptera. Quart. Rev. Biol. 12: 135.

48). Muller, H. I. 1935 On the dimensions of chromosomes and genes in Dipteran salivary glands. Amer. Nat. 69: 405.

49). Painter, T.S. 1933 A new method for the study of chromosome rearrangement and the plotting of chromosome maps. Science N.S. 78: 585

50). - 1934 A new method for the study of chromosome aberations and the plotting of chromosome maps in Drosophila melanogaster. Genetics $19: 175$.

51). Painter, T.S. and Griffen, A.B. 1937 The structure and the development of the salivary gland chromosomes of Simulizm. Genetics. 22.612.

52). Paulsen, D.F. and C.W. Metz 1938 Studies on the structure of nucleolus forming regions and related structures in the giant salivary gland chromosomes of Diptera. J. Morph. 63: 363 . 
53). Pfeiffer, H.H. 1940 Mikrurgische Versuche im polarisierten Lichte zur Analyse des Feinbaues der Riesenchromosomen von Chironomus. Chromosoma. 1: 526.

54). Sinotô, Y, and Yuasa, A. 1935 The spiral structure of salivary chromosomes in Lycoris (Sciara) and Drosophila (a preliminary note), (Japanese, with English résumé). Jap. Journ. Gen. $10: 245$.

55). von Willer, P. und A. Audowa 1933 Mikrodissektion an der Speicheldruise von Chironomus. Protoplasma. 19: 228.

56). Yasui, K. 1935 On the structure of the chromosome in the salivary gland cell of Drosophila melanogaster. Cytologia. 6 : 330. 